Interview

\title{
An Interview with Dr. Joep Geraedts
}

OBM Genetics Editorial Office

LIDSEN Publishing Inc., 2000 Auburn Drive, One Chagrin Highlands, Suite 200, Beachwood, OH, USA; E-Mail: genetics@lidsen.com

OBM Genetics

2022, volume 6 , issue 1

doi:10.21926/obm.genet.2201148
Received: February 17, 2022

Accepted: February 17, 2022

Published: February 22, 2022

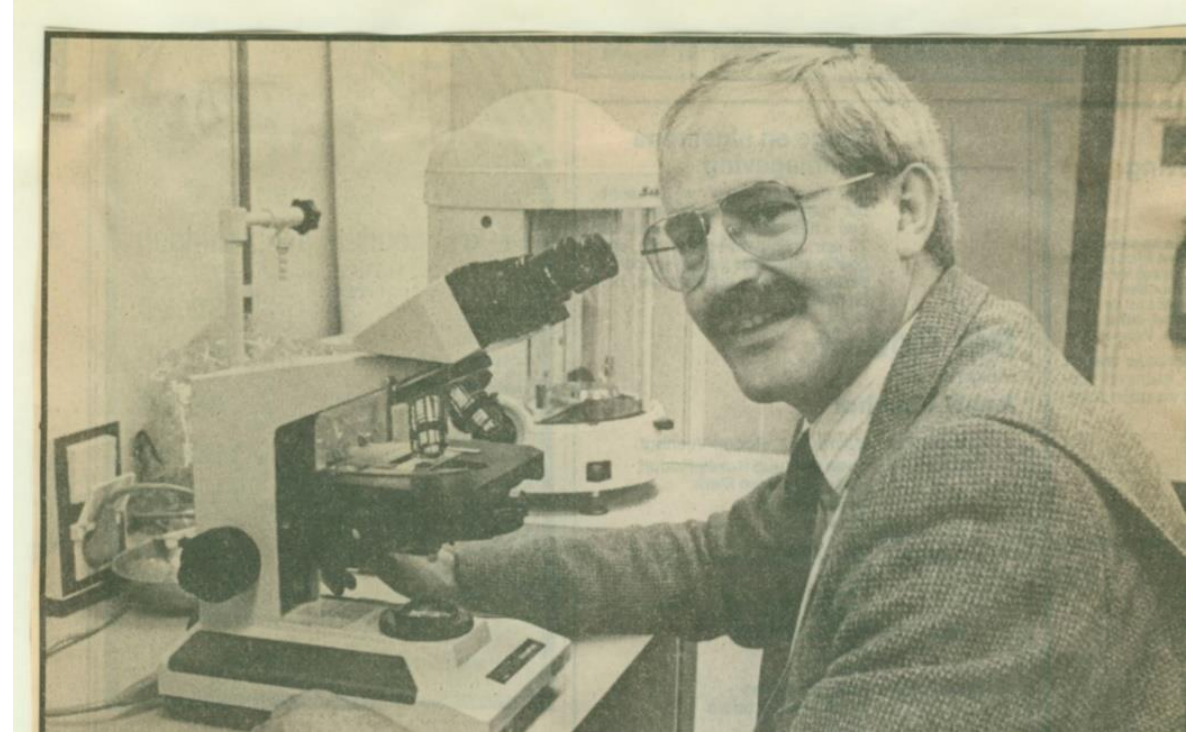

Dr. Joep Geraedts

Dr. Joep Geraedts (1948) obtained a BSc (1969) and MSc (1972) in general biology at the University of Nijmegen. At Leiden University he defended his PhD thesis in 1975. From 1982 to 2013 he was professor of Genetics and Cell Biology at Maastricht University and head of the Department of Clinical Genetics of the University Hospital. In 1995 he started the first and only licensed PGD programme in the Netherlands. He was chairman of the Dutch Society of Human Genetics (1984-

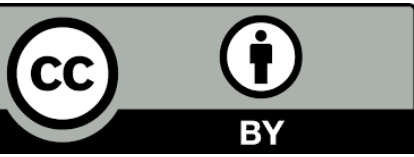

(C) 2022 by the author. This is an open access article distributed under the conditions of the Creative Commons by Attribution License, which permits unrestricted use, distribution, and reproduction in any medium or format, provided the original work is correctly cited. 
1988); chairman of the Dutch Association of Clinical Genetics Centers (2000-2013), chairman of the European Society of Human Reproduction and Embryology (2007-2009) and member of the Dutch Health Council.

\section{Can You Describe in a Few Words Your Personal Background?}

I was born in the Netherlands in a small village in the Province of Limburg, near the German border, 3 years after World War II. Both my parents had primary school education only and they left school at the age of 12. As far as I can judge their IQ was more than high enough for further studies and both would have loved to do so, but their parents couldn't afford to pay for eight children. I am happy that they have always stimulated me. Finally I was the first in our family who went to the university.

\section{Please Tell Us Something about Your Scientific Background?}

I decided to go to the University of Nijmegen to study General Biology. After I obtained my Bachelor degree I had to select three optional subjects for my Masters. From the beginning it was clear to me that genetics would be the main subject and chemical cytology and zoology the minors. My research for all three topics were quite successful and resulted in either presentations at conferences or a journal article [1]. I am still very grateful that my teachers were all very enthusiastic and inspired me tremendously. All three came from abroad and were totally different persons who had in common their devotion to science.

My supervisor in genetics was Dr. Lee T. Douglas from the United States. He used Drosophila melanogaster as a model organism to study irregularities of the Mendelian laws like meiotic drive, segregation distortion and distributive pairing. I was allowed to present my findings at the 2 nd European Drosophila Research Conference in Zürich in 1970.

Besides the progress reports of the experimental work of each student during one afternoon a week, new journal articles and books were presented and discussed. I became very interested in human genetics after discussing "Man and his Future" and "Genetics and the Future of Man" from 1963 and 1965. Thereafter I was looking for a PhD position in this area. I obtained one in Leiden University. My supervisor and promotor was Peter Pearson, who was one of the leading cytogeneticists introducing differential chromosomal staining techniques. I used these to study normal and abnormal variation of chromosomes and especially chromosomal polymorphisms. In 1975 , the year that the University of Leiden was exactly 400 years old, I defended my thesis.

\section{What is Your Main Research Area?}

From the beginning I have been interested in genetics and reproduction. Reproductive genetics deals with the relationship between the genetic material and reproduction and includes the transmission from one generation to the next and also the effects of genetic abnormalities which can hamper reproduction. Finally, I have always been interested in diagnosis of genetic abnormalities in gametes and embryos. 


\section{Considering the Progress in Your Research Area, Could You Please Share Us Some Hot Topics or Cutting-Edge Technologies That You Have Seen Developing in Your Research Field?}

When I started in the early 70ties there was still limited knowledge regarding genetics and the only human reproduction that was possible was natural. Therefore, the ways in which couples with an increased risk could avoid transmitting genetic disease or chromosomal abnormalities were limited as well: to refrain from having children; sperm donation and in some cases prenatal diagnosis. After more genetic knowledge became available and especially molecular methods to study genes at the DNA level new diagnostic options arrived. After Steptoe and Edwards had introduced IVF the number of treatment options increased spectacularly. At the end of my career the following topics could be added: Donation of oocytes; Invasive Prenatal Diagnosis (PND) for almost all genetic disorders; Non-Invasive Prenatal Diagnosis (NIPD); Preimplantation genetic diagnosis (PGD); Spindle transfer or pronuclear transfer to avoid MtDNA defects and Genome Editing.

\section{Which Topics Are Included? In Your Opinion, What Challenges and Developments Can We Expect to See in Among These Topics?}

In my opinion many of the challenges are less technical but the clinical application has more ethical and societal aspects and impact. About 20 years ago I was able to bring together experts from the European Society of Human Genetics (ESHG) and the European Society of Human Reproduction and Embryology (ESHRE) to discuss the developments at the interface between clinical genetics and assisted reproduction. Among other topics the need for proper genetic counselling before any new technique can be applied and the lack of randomized clinical trials to substantiate that newly developed techniques are both effective and efficient was clear. Studies are also needed in order to address issues related to the impact of assisted reproduction on epigenetic reprogramming of the early embryo. Furthermore, the legal landscape regarding assisted reproduction is evolving but still remains very heterogeneous and often contradictory. The lack of legal harmonization and uneven access to infertility treatment and preimplantation and prenatal genetic diagnosis fosters considerable cross-border reproductive care in Europe and beyond.

\section{As an Experienced Researcher in This Field, What Do You Consider to Be Key Aspects of Research That Apply to Clinical Practice?}

Applied research should be beneficial for the patient who is asking for help. In case of a rare disorder the diagnosis will be welcomed. However, unless in other medical disciplines treatment of patients presenting with a genetic disease is only possible in a very small minority of cases. However, treatment at the level of the family, which means stopping the transmission of the disease, is helping the next generation.

\section{Did you Also Offer Training and/or Further Education in Your Area?}

Over the years I was involved in education at all sorts of levels: teaching at the undergraduate level, practical training in the laboratory, supervising Master and PhD thesis. I have also been dean of a so called Transnational University in which the University of Hasselt (Belgium) and the University of Maastricht in the Netherlands together offered a bachelor training program in the life 
sciences. Furthermore, as a biologist I have been the chairman of the exam committee of the Medical Faculty.

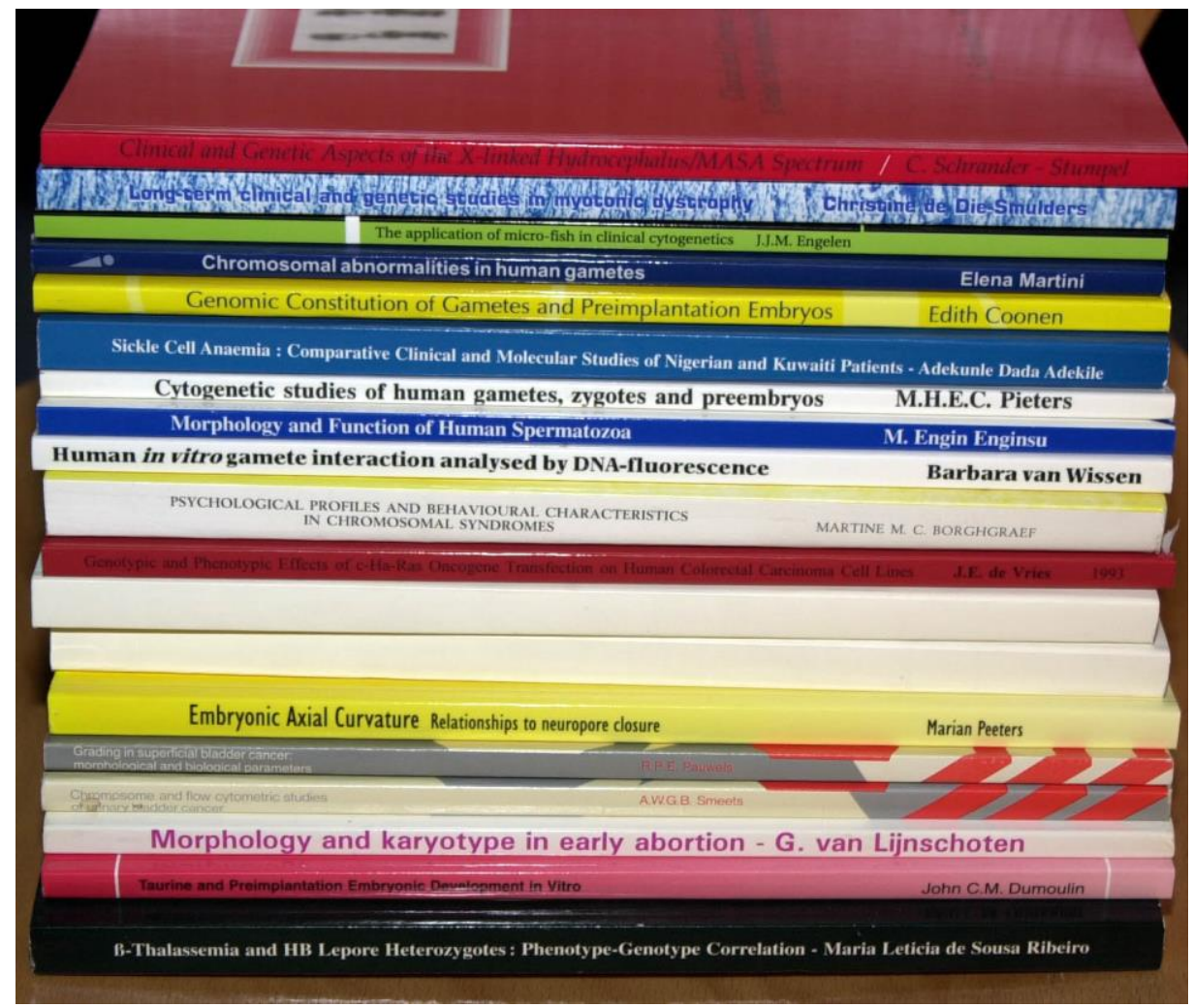

Collection of theses of Dr. Geraedts's PhD students.

\section{How Did Patients Benefit from Your Research?}

My major contribution was the introduction and development of preimplantation genetics. My center in Maastricht was and still is the only one in the Netherlands having a license to perform this. Over the years the number of patients making use of this alternative has grown from a few to more than 500 each year. To avoid the need to come to Maastricht for IVF there is a cooperation with another three hospitals in the country. They do the IVF and take to biopsies which are then send to the diagnostic center in Maastricht.

\section{Let Us Know How You Balance Your Job with Privacy? What Are Your Secrets of Success for This?}

I have never worked according to standard working hours. Furthermore, I have been travelling abroad quite a lot. This means that my family was not seeing me regularly. I tried to be at home as many weekends as possible and we spend together the winter and the summer holidays. Only now after two years of COVID-19 I have the idea that Zoom and Teams could have been a good replacement making many travels unnecessary.

\section{What Are Your Future Plans?}

At the end of my scientific career and at my age the number of future plans is limited. I am writing a biography and of course I hope to keep contributing to OBM Genetics. 


\section{References}

1. Wanka F, Geraedts J. Effect of temperature in the regulation of DNA synthesis in synchronous cultures of Chlorella. Exp Cell Res. 1972; 71: 188-192.

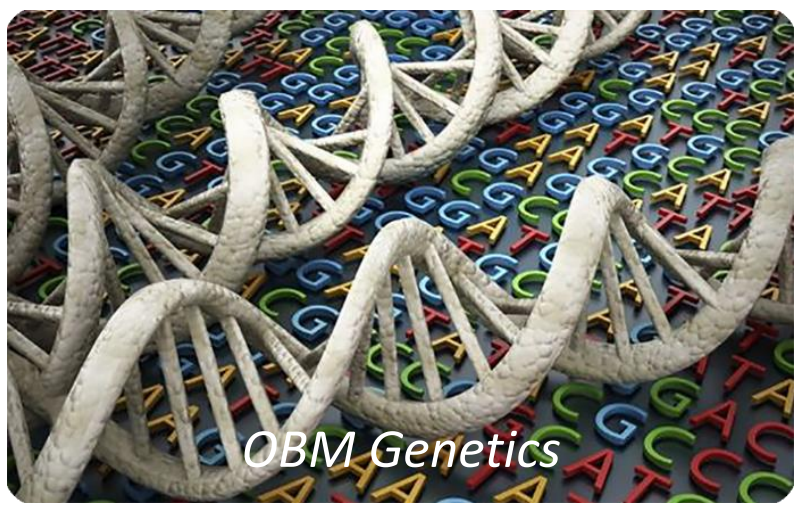

Enjoy OBM Genetics by:

1. Submitting a manuscript

2. Joining in volunteer reviewer bank

3. Joining Editorial Board

4. Guest editing a special issue

For more details, please visit:

http://www.lidsen.com/journals/genetics 